\title{
Holistic Architecture for Music Education: A proposal for empirical research in educational situations
}

\author{
Angel-Alvarado, Rolando ${ }^{\text {a1 }}$; Wilhelmi, Miguel R. ${ }^{a}$ and Belletich, Olga ${ }^{\text {a }}$ \\ ${ }^{a}$ Department of Psychology and Pedagogy, Public University of Navarra, Spain ${ }^{2}$
}

\begin{abstract}
Holistic Architecture for Music Education (HAME) arises as a Design-Based Research, that is, it is an interdisciplinary research approach based on mixed research methods, which attempts understanding empirical phenomena from music education complexity. The HAME' structural design poses a preliminary study of phenomena, the formulation of a research hypothesis, fieldwork in real-world situations and, finally, an analysis of data collected during the fieldwork with the intention of contrasting the hypothesis. This study aims to explore the technical suitability of the HAME in music education's empirical research. Results demonstrate consistency between four phases of the structural design, in addition to prove the empirical complexity of organisational structures in music classrooms. In conclusion, the HAME is understood as an interdisciplinary educational research approach, which is holistically described as it connects theoretical currents of the social sciences and humanities with actual educational situations of music education. As a consequence, the HAME provides theoretical and practical knowledge about music education.
\end{abstract}

Keywords: Empirical research; music education; organisational structure; educational interaction process; classroom environment; teacher behaviour.

\footnotetext{
${ }^{1}$ The first author has been supported by the National Commission for Scientific and Technological Research from Chile (CONICYT) through a doctoral scholarship [grant number 72160365].

2 The authors acknowledge to the Sibelius Academy’s MuTri Doctoral School for discussing this project in the frame of the Music Education Doctoral Studies. In this line, the authors especially thank Heidi Westerlund for her valuable comments oriented toward the HAME's refinement.
} 


\section{Introduction}

The Holistic Architecture for Music Education (hereafter HAME) is an interdisciplinary research approach that tries conducting empirical studies in the frame of music education. It is useful both researchers and educators due to it provides theoretical and practical knowledge within teaching and learning situations since educational activities are theoretically grounded, empirically contrasted, and they could be repeatable. In this regard, HAME sticks to the idea that "the research and theoretical bases for music education must simultaneously be refined and radically broadened both in terms of their theoretical interest and practical relevance” (Mayday Group, 2009, p. xxxv).

The Holistic's concept possesses multiple meanings. The holistic research approach implies mixed research methods, so the same phenomenon is analysed from different viewpoints (Lichtman, 2013; Creswell, 2014). For instance, the quantitative design allows collecting macrosocial data while qualitative procedures delve into specific issues. In addition to this, the holistic research approach also understands results as photography of a specific moment within a continuum construction process (Ofir, Schwandt, Duggan, \& McLean, 2016), that is, outcomes depict a here-and-now of educational situations (Westerlund, 2003).

The Architecture's concept is considered a holistic term as it is linked to arts, humanism, social sciences and engineering (Wallen, 1986; Rabbat, 2002). The Music's concept also is understood from a holistic perspective since it is understood as an "art, craftsmanship and everyday culture” (Georgii-Hemming \& Lilliedahl, 2014, p. 140). Lastly, the Education's concept has a holistic understanding due to teaching and learning activities are analysed since educational sciences, participating different agents in educational situations, such as teachers, students, and so on. Therefore, the Design-Based Research is the HAME's foundation because, since the Didactical Engineering (Artigue, 2015), it fulfils the holistic research approach for music education. In light of this, the HAME's name makes reference to the holistic sight of real-world music education, so it is intimately linked to complex thinking.

In this study, we will explore the technical suitability of the HAME for conducting empirical research in the field of music education. In order to comply this aim, one research is conducted for establishing whether HAME is an interdisciplinary research approach or not, which implies focusing simultaneously on different educational situation's agents using mixed research methods. 


\section{A study focused on organisational structure in music education's classroom}

HAME establishes a four-phases structural design. The first phase implies a preliminary study of epistemological, institutional and didactic situations of the phenomenon. The second phase corresponds to prospective analysis, which is the moment for establishing both research questions, aims, hypothesis, mixed research methods, and so on. In HAME, the research hypothesis is essential for the structural design's validity by reasons linked to the musical Bildung's hermeneutic circle (Nielsen, 2007; Georgii-Hemming \& Lilliedahl, 2014). The third phase is the fieldwork as it involves data collecting in an actual education system. Lastly, the fourth phase is the retrospective analysis, which analyses data collected in the fieldwork. The obtained findings during the retrospective analysis are contrasted with the research hypothesis, so structural design possesses an internal validity that is holistically described. Considering the HAME' structural design, the announced study is conducted next.

\subsection{Preliminary study and prospective analysis}

Different organisational structures are observed in the classroom. On the one hand, institutions focused on one-to-one lessons, such as conservatories, are mainly promoting a didactic triangle where iteratively interacts the learning content, student, and teacher (Lilliedahl, 2015; Carey, Harrison, \& Dwyer, 2017). On the other, collaborative learning would be, apparently, encouraged by formal schools (Welch, 2009) since it is based on social constructivism (Westerlund, 2003). In light of this, HAME postulates a network of didactical interactions where iteratively interacts the student, teacher, and school community. These agents are forced to interact with the learning content because it is understood as a connecting link between curriculum theory and teaching-learning procedures (Lilliedahl, 2015; Cheon, Reeve, Lee \& Lee, 2018). Considering these epistemological and institutional factors, the didactic situation emphasises that teacher play a determinant role in the classroom, to the point that educator could influence in student's behaviours (Madariaga \& Arriaga, 2011; Hallam, Creech, \& McQueen, 2017).

HAME claims nevertheless that both organisational structures in the classroom are not enough for understanding the complexity of didactical interactions since they lose sight of external factors of teaching-learning situations. Therefore, the network of didactical interactions also includes next four anthropological elements inherent to music education: facilities and educational resources (Angel-Alvarado \& Lira-Cerda, 2017), curriculum (Belletich, Wilhelmi, \& Angel-Alvarado, 2016), meta-economy (London School of Economics and Political Science, 2012), and globalisation culture (Partii \& Karlsen, 2010).

In this study, the prospective analysis proposes delving into organisational structures in the Spanish Primary Education's music classrooms, mainly focusing on teacher agent. The aim 
is to determine kind of organisational structure in the classroom that teachers establish with their students, so this study becomes relevant for HAME because it could open new lines of research in the frame of teaching and learning situations. Teachers and students from three schools integrated the participant sample. Mixed research methods have been considered through psychological scales, questionnaires, interviews and observation procedures. Lastly, the hypothesis poses that both didactic triangle and network of didactical interactions are observed in the music education system.

\subsection{Fieldwork}

Two educators were interested in music theory in the frame of their instructional activities, to the point that both have mainly established one-to-one assessments. The students recognised that music theory is important in educational situations, so the individualistic perspective has been ratified. As a result, the didactic triangle is observed since the teaching content, student, and teacher iteratively interacted. In the other case, the educator was interested that learners conducted their activities within a school community, promoting that each student provided constructive feedback to their classmates during formative and summative assessments. Learners ratified the collaborative learning. As a consequence, the network of didactical interactions is observed due to the student, teacher, and school community iteratively interacted, taking the learning content as a connecting link. In all educational cases, anthropological elements inherent to music education has influenced on educational situations. Lastly, it is necessary to indicate that didactic triangle alludes to teaching content because educators are focused on what they want to teach, whereas network of didactical interactions has expressed learning content since educators are centred on what students need or want to learn.

\subsection{Retrospective analysis}

Four basic didactics positions (Nielsen, 2007; Georgii-Hemming \& Lilliedahl, 2014) play a determinant role in HAME' data analysis. The first position is the basic subject didactics that comprises music education since curriculum. Secondly, ethno-didactics implies daily musical experiences. Challenge didactics is the third basic didactics position, promoting critical and civic thinking. Finally, philosophical anthropological didactics articulates the emotion and logic in each person.

In this study, the basic subject didactics showed that two educators focused their teaching on academicist approach (Manrique, Revilla, Lamas, 2014) while the other teacher considered musical knowledge as a mean for encouraging social skills. The ethno-didactics demonstrated that teacher agent could determine the educational environment in the classroom by means of organisational structure established by her/him. The challenge didactics displayed that collaborative learning encourages critical and civic thinking of 
students through their active participation in the frame of assessments. Finally, the philosophical anthropological didactics would indicate that students prefer lessons based on social constructivism since they could autonomously manage their musical resources.

The retrospective analysis has confirmed then the research hypothesis as both didactic triangle and network of didactical interactions are observed in the music education system. This study has demonstrated therefore that teachers establish different kinds of organisational structures in the classroom, which would have an impact on their students. In light of this, the HAME' structural design possesses an internal validity that is holistically described.

From a theoretical perspective, this study proposes to discuss organisational structures in music education systems as it provides relevant empirical data referred to the didactic triangle and network of didactical interactions. Considering the limited sample' size, research results are particularly revealing for music education research since a greater sample would show likely more organisational structures in the classroom. This study could be opening then new lines of research in the frame of teaching and learning situations due to educators and students think in organisational structures in music classrooms from different viewpoints. In light of this, organisational structure's observation and analysis have become essential activities in the third phase of HAME, fieldwork.

From a practical perspective, research outcomes are useful for the participant teacher sample at least, as results would promote pedagogical reflection centred on teacher's impact on the student, both in their identity, motivation, self-regulation, and so forth. In addition to this, research results also are useful for education management as analysed schools could consider organisational structures in the classroom for designing and executing improvement plans.

\section{Conclusions}

HAME' structural design is described as an interdisciplinary research approach because it discloses how different educational agents are interrelated, trying to establish the relevance that each agent holds in the classroom's organisational structure. Specifically, the preliminary study understands phenomena from epistemological, institutional and didactic dimensions. The prospective analysis enables the formulation of research questions, aims, hypothesis, and so on. The third phase is the fieldwork, which considers the organisational structures' observation in the classroom during data collecting. Finally, the retrospective analysis considers four basic didactics positions for analysing collected data. The HAME's validity is demonstrated through a contrast between the retrospective analysis and research hypothesis, describing holistically such contrast's process since findings are understood as 
the photography of a specific moment of the educational situation, using mixed research methods. In conclusion, the consistency between four phases of the HAME' structural design has been empirically proven, therefore, it is confirmed the technical suitability.

So far, HAME is successfully applied in studies that are being carried out in different countries. Both the classroom's organisational structure and four-phases structural design are adjustable to any educational environment, so it is feasible that HAME could be applied in a wide variety of formal, non-formal or higher education systems.

\section{References}

Angel-Alvarado, R., \& Lira-Cerda, J. P. (2017). Educational facilities for Music Education according to the social representation of Chilean students. Electronic Journal of Music in Education, (40), 19-31. doi: 10.7203/LEEME.40.10412

Artigue, M. (2015). Perspectives on Design Research: The case of Didactical Engineering. In A. Bikner-Ahsbahs, C. Knipping, \& N. Presmeg (Eds.), Approaches to qualitative research in mathematics education (pp. 467-496). Dordrecht: Springer.

Belletich, O., Wilhelmi, M. R., \& Angel-Alvarado, R. (2016). La educación musical en la formación básica en España: El problema de la dispersión curricular. Perspectiva educacional, 55(2), 158-170. doi: 10.4151/07189729-Vol.55-Iss.2-Art.454

Carey, G., Harrison, S., \& Dwyer, R. (2017). Encouraging reflective practice in conservatoire students: A pathway to autonomous learning? Music Education Research, 19(1), 99-110. doi: 10.1080/14613808.2016.1238060

Cheon, S. H., Reeve, J., Lee, Y., \& Lee, J. (2018). Why autonomy-supportive interventions work: Explaining the professional development of teachers' motivating style. Teaching and Teacher Education, 69: 43-51. doi: 10.1016/j.tate.2017.09.022

Creswell, J. W. (2014). Research design: Qualitative, quantitative and mixed methods approaches. Los Angeles, CA: SAGE

Georgii-Hemming, E., \& Lilliedahl, J. (2014). Why "what" on the content dimensions of music didactics. Philosophy of Music Education Review, 22(2), 132-155.

Hallam, S., Creech, A., \& McQueen, H. (2017). What impact does teaching music informally in the classroom have on teachers, and their pedagogy? Music Education Research, 19(1), 42-59. doi: 10.1080/14613808.2015.1122749

Lichtman, M. (2013). Qualitative research in education: A user's guide. Thousand Oaks: SAGE.

Lilliedahl, J. (2015). The recontextualisation of knowledge: towards a social realist approach to curriculum and didactics. Nordic Journal of Studies in Educational Policy, 1(1), 40-47. doi: 10.3402/nstep.v1.27008

London School of Economics and Political Science. (2012). The impact of three London conservatoires on the UK and London economies. London: LSE.

Madariaga, J.-M., \& Arriaga, C. (2011). Analysis of the educational practice of music teachers and their relationship with student motivation. Cultura y Educación, 23(3), 463-476. doi: 10.1174/113564011797330234 
Manrique, L., Revilla, D., \& Lamas, P. (2014). Theoretical approaches underlying primary education curricula in Peru. In W. Pinar (Ed.), International handbook of curriculum research (pp. 376-390). New York: Routledge.

Mayday Group (2009). Action for change in music education. In A. Regelski \& T. Gates (Eds.), Music education for changing times: Guiding visions for practice (pp. xxxixxxvii). Dordrecht: Springer.

Nielsen, F. V. (2007) Music (and Arts) Education from the point of view of didaktik and bildung. In L. Bresler (Eds.), International handbook of research in arts education (pp. 265-285). New York: Springer.

Ofir, Z., Schwandt, T., Duggan, C., \& McLean, R. (2016). Research quality plus $[R Q+]$ : A holistic approach to evaluating research. Ottawa: IDRC/CRDI.

Partii, H., \& Karlsen, S. (2010). Reconceptualising musical learning: New media, identity and community in music education. Music Education Research, 12(4): 369-382. doi: 10.1080/14613808.2010.519381

Rabbat, N. (2002). The boundaries of architectural education today. In A. M. A. Salama, W. O’Reilly, \& K. Noschis (Eds.), Architectural education today: Cross-cultural perspective (pp. 149-154). Lausanne: Comportements.

Wallen, G. (1986). The scientification of architecture. In G. Böhme \& N. Stehr (Eds.), The knowledge society: The growing impact of scientific knowledge on social relations (pp. 161-182). Dordrecht: D. Reidel Publishing Company.

Welch, G. F. (2009) Ecological validity and impact: Key challenges for music education research. In A. Regelski \& T. Gates (Eds.), Music education for changing times: Guiding visions for practice (pp. 149-159). Dordrecht: Springer.

Westerlund, H. (2003). Reconsidering aesthetic experience in praxial music education. Philosophy of Music Education Review, 11(1): 45-62. 